\title{
Evolution of homomorphic sporophytic self-incompatibility
}

\author{
D. Charlesworth,
}

Department of Biology, University of Chicago,

915 E 57th St., Chicago, Illinois 60637, U.S.A.

A population genetic model is described for the evolution of sporophytic self-incompatibility by successive mutations to active incompatibility alleles from an ancestral compatibility, $\boldsymbol{S}_{f}$, allele, homozygotes for which are capable of selffertilisation. For spread of the active incompatibility alleles there must be strong inbreeding depression. It is shown that polymorphism for the ancestral allele and the active alleles is generated, unless the number of active alleles becomes very large. Thus, although there is selection for alleles that cause outcrossing, such polymorphic populations would not be completely outcrossing, but would have selfing rates between zero and the selfiing rate of the homozygote for $S_{f}$. The equilibrium frequencies of the active alleles depend on whether dominance or independent action is assumed for the alleles in the pistil. In either case the equilibrium allele frequencies are higher than would be the case for gametophytically acting alleles.

\section{INTRODUCTION}

Sporophytic self-incompatibility systems exist in several flowering plant families (De Nettancourt, 1977). Until recently, this type of system was known only in the crucifers and composites and it was thought that, apart from species with heterostyly, sporophytic self-incompatibility was a minor feature of angiosperm breeding systems, compared with the much commoner and more widespread gametophytic systems which are now known from 14 or 17 different angiosperm families (De Nettancourt, 1977; Hummel et al., 1982, Fuchinoue, 1979). Sporophytic self-incompatibility systems have now been discovered in four more families (Convolvulaceae: Martin, 1968; Kowyama et al., 1980, Betulaceae: Thompson, 1979; Germain et al., 1981; Me and Radicati, 1983, Caryophyllaceae: Lundkvist, 1979, Sterculiaceae: Jacob, 1980). So far, most attempts to think about the evolution of homomorphic self-incompatibility have either been vague about what type of system is being considered (Whitehouse, 1950; Bateman, 1952, p. 291), or have explicitly considered the gametophytic type of system (Charlesworth and Charlesworth, 1979b).

There has been some speculation about the possibility that one type of system may evolve into the other, presumably by changing the time of expression of the self-incompatibility locus, rather than by a change to a new self-incompatibility locus. It has been suggested several times that the gametophytic type of system arose first, and was later replaced by the sporophytic type in some groups (e.g., Pandey, 1958, 1960), but apart from Muenchow's (1982) model for the evolution of the distyly type of self-incompatibility from a multilocus sporophytic type, the only explicit model that includes a selective force that could cause this change is that of Beach and Kress (1980). These authors point out that in gametophytic systems, mutations to alleles that allow incompatible pollen grains to escape the self-incompatibility reaction would be selected for. They suggest that it might therefore be advantageous for maternal plants to detect incompatible pollen as early as possible, thus preventing male gametyophyte gene expression and blocking any possibility for selection for such mutations. However, this is at best a very weak force, since it depends on the occurence of mutations and there would be no selective advantage to a maternal mutant that inhibits incompatible pollen early, unless the pollen carries the mutation; in other words, this model requires the simultaneous occurrence of two very rare events. The model also has the difficulty that it 
postulates that the mutation conferring a sporophytic system changes the recognition system of the maternal plant, not the timing of expression of the self-incompatibility gene in the male parent. Other criticisms are made by Gibbs (1986). A variant of this model might be imagined, in which the advantage to maternal plants that express the self-incompatibility on the pollen (i.e. sporophytically) would come from their ability to reject pollen carrying mutations to self-fertility. Such mutations might occur at any of several loci, so that the probability that a plant will produce some pollen grains carrying such mutations could be nonnegligible. However, it is not clear that expression of the incompatibility locus during pollen formation would in reality have the proposed effect in a species starting with a gametophytic system, because it is known that heterozygous diploid pollen which has two different alleles at the selfincompatibility locus may often behave as compatible on maternal plants carrying those alleles (see for example De Nettancourt, 1977).

Recently, Zavada and Taylor (1986) argued, on the basis of pollen morphology of modern (Zavada, 1984) and fossil angiosperms, that sporophytic systems were the earliest type of selfincompatibility in the flowering plants, and even that the gametophytic type of system may be secondarily derived from the sporophytic type (but see Gibbs and Ferguson, 1987). It is therefore important to think about how the sporophytic type of system could evolve from an initially selfcompatible state, and about the possibility of the evolutionary transition from sporophytic to gametophytic self-incompatibility. I will compare the results with those of an otherwise similar model for the evolution and maintenance of gametophytically controlled self-incompatibility. I will also consider the evolution of the type of sporophytic incompatibility system found in distylous plants.

The main difficulty in modelling the evolution of sporophytic self-incompatibility is that there may be interactions between the two alleles carried in an individual. The situation appears to be much simpler in gametophytic systems, in which alleles apparently act independently in the pistil. In sporophytic systems, one allele may be dominant to the other, either in the pollen or in the pistil, or in both, or both may be expressed (referred to as "independent action") in one or both of these tissues, or the heterozygote may express an incompatibility type different from that of either of the homozygotes (De Nettancourt, 1977); in some cases, there may be mutual weakening of the selfincompatibility reactions. In distylous species, there are only two allelic incompatibility genes (actually there is probably a tightly linked pair of loci, one for the pollen reaction and one for the pistil reaction: Ernst, 1936; Baker, 1966), and the reaction associated with one of the two flower types is dominant to the other in both pollen and pistil. Usually, the reaction of the short-styled type is dominant (reviewed in Ganders, 1979). To study the evolution of sporophytic incompatibility, one must therefore consider various possible types of interaction between the alleles, and I have considered the case of dominance or independent action in the pollen and pistils of heterozygotes, using the model of Sampson (1974) which assumes alleles at various different dominance levels. The details of the models are explained below.

\section{MODELS AND ANALYSIS}

\section{Model with a self-fertility allele and a single active $S$ allele}

This simple system can be treated analytically. The model assumes a population with a single selffertility allele $S_{f}$ and an active self-incompatibility allele $S_{1}$ at the same locus which is assumed to be dominant to $S_{f}$. Heterozygotes were therefore assumed to have pollen of incompatibility type 1, i.e., they were self-incompatible. The homozygous genotype $S_{1} S_{1}$ is thus not produced, and there are only two genotypes in the system, $S_{1} S_{f}$ with frequency, $P_{1}$, say, and $S_{f} S_{f}$ with frequency $1-P_{1}$. The matings are shown in table 1 .

I assume that ovule production is the same for $S_{1} S_{f}$ and $S_{f} S_{f}$, and that the probability that an ovule of a $S_{f} S_{f}$ plant is selfed is $s$. The products of selfing are assumed to suffer from inbreeding depression, such that their probability of surviving is $(1-\delta)$ of the value for a progeny not produced by selfing. The probability that a non-selfed ovule is fertilised is denoted by $f$. Writing $p_{1}^{\prime}$ for the frequency of the $S_{1}$ allele, and $P_{1}^{\prime}=2 p_{1}^{\prime}$ for the frequency of the self-incompatible genotype $S_{1} S_{f}$ in the next generation, we have

$$
P_{1}^{\prime}=\left[\left(1-P_{1}\right)(1-s) p_{1} f+\frac{P_{1}}{2} f\right] / \bar{w}=2 p_{1}^{\prime} .
$$

where

$$
\bar{w}=\left(1-P_{1}\right)\{s(1-\delta)+f(1-s)\}+P_{1} f .
$$

The $S_{1}$ allele therefore increases if

$$
\begin{aligned}
& f\left\{\left(1-P_{1}\right)(1-s)+1\right\} \\
& \quad>2\left[\left(1-P_{1}\right)\{s(1-\delta)+f(1-s)\}+P_{1} f\right] .
\end{aligned}
$$


Table 1 Parent and progeny genotypes with a self-compatbility alle, $S_{f}$, and a single active $S$ allele

\begin{tabular}{|c|c|c|c|c|}
\hline & & & Outcrossi & th pollen \\
\hline & & Selfing & from $S_{f} S_{f}$ & from $S_{1} S_{f}$ \\
\hline Maternal genotype & Frequency & $s$ & $(1-s)\left(1-P_{1}\right)$ & $(1-s) P_{1}$ \\
\hline $\begin{array}{l}S_{f} S_{f} \\
\text { (no incompatibility) }\end{array}$ & $1-P_{1}$ & $S_{f} S_{f}$ & $S_{f} S_{f}$ & $\begin{array}{l}S_{f} S_{f}, S_{1} S_{f} \\
1: 1\end{array}$ \\
\hline $\begin{array}{l}S_{1} S_{f} \\
\text { (incompatibility type 1) }\end{array}$ & $P_{1}$ & - & $\begin{array}{l}S_{f} S_{f}, S_{1} S_{f} \\
1: 1\end{array}$ & - \\
\hline
\end{tabular}

By equating the two sides of this expression, it is easy to show that there is an equilbrium when

$$
\hat{P}=\frac{2 s(1-\delta)-f s}{2 s(1-\delta)-f(1+s)} .
$$

When $f=1$ this becomes

$$
\hat{P}=\frac{s(2 \delta-1)}{1+s(2 \delta-1)} \text {. }
$$

which requires $\delta>\frac{1}{2}$ for $\hat{p}_{1}>0$. The condition for the $S_{1}$ allele to invade becomes harder if $f<1$. When $\delta=1-f / 2$, the equation for equilibrium above shows that $\hat{P}_{1}=0$ for all values of $s$. In other words, as $f$ gets lower, the value of $\delta$ necessary for invasion increases. Thus $\delta>\frac{1}{2}$ is a necessary condition for the self-incompatibility allele to invade. This is not surprising, given earlier results of others (e.g., Lloyd, 1979; Lande and Schemske, 1985). Table 2 shows some results of this model. It is evident that if $f$ is not close to 1 , the chance is very low that a self-incompatibility allele will invade, unless there is very severe inbreeding depression. High selfing is not, however required, provided that $f$ is close to 1 .

\section{Model of the system with multiple active $S$ alleles and a self-fertility allele}

The next question studied was whether a second mutation, and subsequent mutations, to active $S$ alleles would spread into a population which had one such allele and a self-fertility allele. The fate of the self-fertility allele when several active $S$ alleles are present was also of interest. To answer these questions, I wrote a computer program to calculate genotype frequencies after a single generation of mating according to the compatibility types specified by the alleles. All genotypes were assumed to have equal numbers of ovules, but it was assumed as above that non-selfed ovules had a probability of fertilisation equal to $f(f \leqq 1)$, so that genotypes capable of selfing would have a higher fraction of their ovules fertilised than genotypes wholly dependent on the arrival of compatible pollen. However, the calculations did not include the possibility that female fertility might be limited by the supply of compatible pollen, which might lower the progeny output from any female genotypes that were compatible only with rare pollen types. It is reasonable to ignore this possibility, because it is unlikely to occur in the situation which I am modelling, in which a rare allele for a new incompatibility type enters the population. When such an allele is rare, its carriers will be at least as compatible with the pollen present in the population as are the existing population members, and its female fertility would thus be as high or higher than theirs. As the allele increases in frequency and reaches equilibrium, the female fertility of its carriers would tend to decrease because more of the pollen present in the population would have the new incompatibility type, but the effect would not be to decrease the female fertility of those genotypes below that of other genotypes in the population.

Table 2 Equilibrium frequency of the genotype $S_{1} S_{f}$ with a self-compatibility allele and a single active $S$ allele

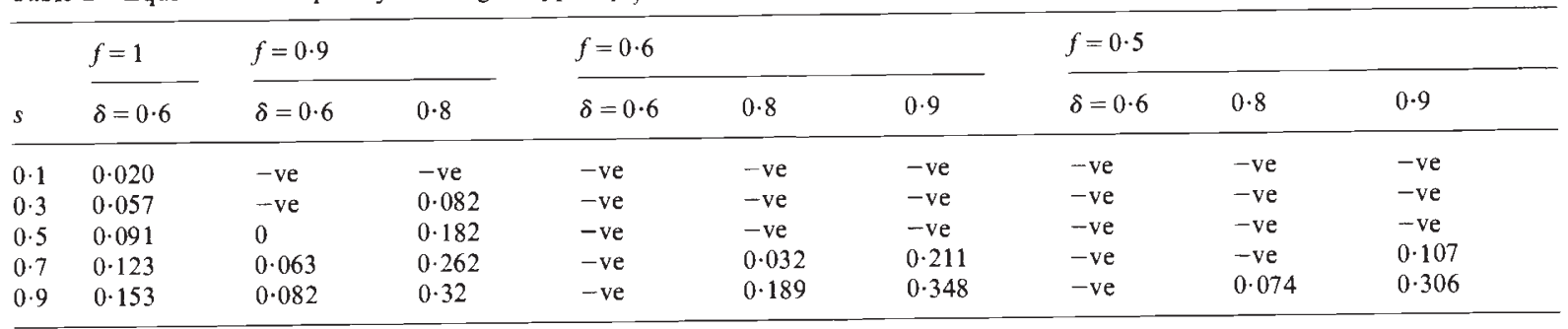


The genetic model studied was a generalisation of the model of Sampson (1974) with a number of different levels of alleles. In the pollen, alleles at the same level were assumed to act independently so that the incompatibility types of both alleles would be expressed, but alleles at one level were assumed to be recessive to alleles at higher levels, so that for example a heterozygote for an allele at level 1 and an allele at level 2 would express only the incompatibility type of allele 2 . Two models for the interactions in the pistil were studied. In the first model (IND), all alleles were assumed to act independently regardless of their level, while in the second model (DOM) the alleles were assumed to behave the same in pollen and pistil, with alleles of lower levels recessive to those of higher levels. In addition, the model includes the possibility of a self-fertility allele $S_{f}$, which was designated $S_{0}$. The other alleles were designated $S_{1}$ to $S_{n}$, with $n_{i}$ alleles at the $i$ th level, and with each allele having a different incompatibility type. $S_{f}$ was assumed to be the bottom recessive allele in the series; thus the $S_{f} S_{k}$ heterozygote would express only $S_{k}$ and would be self-incompatible even though it carries $S_{f}$. The number of levels could be specified in general (I used a maximum of 5), and the number of alleles at each level could be altered at will and could be equal for all levels, or different for different levels.

Consider first genotypes with no self-compatibility $\left(S_{f}\right)$ alleles. To perform the calculation, each genotype is taken in turn as maternal parent. First the program determines whether the genotype is a homozygote or a heterozygote, what levels of alleles it carries and thus, given the allele numbers, the incompatibility types that it expresses. Each genotype is then considered as a potential pollen donor and the first step is to determine whether it is compatible with the maternal genotype. To do this the program finds, in the same way, which incompatibility types the pollen donor genotype expresses; if none of these is the same as any of the types expressed by the maternal genotype, the pollination is compatible. For each compatible combination, the appropriate elements of the matrix of progeny genotype frequencies are incremented according to the output of that genotype from that combination of maternal and paternal parental genotypes, taking into account the frequencies of the maternal genotypes in the parental population and the weighting factor, $f$, defined above which takes into account the fact that all these progeny are due to outcrossing. To incorporate the assumption that female fertility was not limited by the supply of compatible pollen, the total contributions from each maternal genotype were normalised to be equal to $f$.

Genotypes carrying $S_{f}$ heterozygous with active $S$ alleles were dealt with in the same way as just described, but the maternal genotype homozygous for $S_{f} S_{f}$ was treated separetely because it is capable of self-fertilisation. For that genotype, the contribution to progeny via selfing is $s(1-\delta)$ where $s$ is the selfing rate, $\delta$ is the inbreeding depression parameter defined above, and they are all of the $S_{f} S_{f}$ genotype. The contributions via outcrossing were calculated in a similar way to those for the self-incompatible genotypes, except that pollen from all genotypes was compatible.

When all genotypes had been considered as maternal parents in this way, the matrix of progeny genotype frequencies was normalised to 1 and used as the matrix of genotype frequencies for a new round of calculations of the same kind. The process could be repeated for as many generations as needed to reach equilibrium.

\section{Results of the multi-allele models}

Table 3 shows the equilibrium frequencies of $S_{f}$ and of active $S$ alleles in runs with alleles at up to three levels. The same equilibria were found whether the $S_{f}$ allele was initially fixed, and the active $S$ alleles introduced in sequence, or was introduced at low frequency into a population at equilibrium for the active $S$ alleles, and the two models of gene action in the pistil, independent (IND) and dominant (DOM) gave similar results, with slightly higher equilibrium frequencies for the active $S$ alleles in the DOM model. All the results shown in the table were obtained assuming an $f$ value of 1 . When a value of 0.9 was used, the $S_{f}$ allele had higher frequencies than those shown. When a second, or later, allele was introduced, the value of $\delta$ was not changed. In reality, it is most likely that inbreeding depression would get stronger as the population became more outcrossing, and it is a conservative assumption to hold its value constant, in the sense that invasion of the population by the $S_{f}$ allele is less likely after the population has been outbred for some time than one would predict from the parameters of the initial population before the $S$ alleles arose.

It is clear that with this model successive active $S$ alleles can invade the population. The rates of increase of active $S$ alleles are quite high. For example, assuming values of $s=0.7$ and $\delta=0.6$, the rate of increase of a new allele introduced at a frequency of 0.001 into a wholly $S_{f} S_{f}$ population was $1 \cdot 121$. When active $S$ alleles were already 
Table 3 Equilibrium allele frequencies of active $S$ alleles and a self-fertility allele $S_{f}$

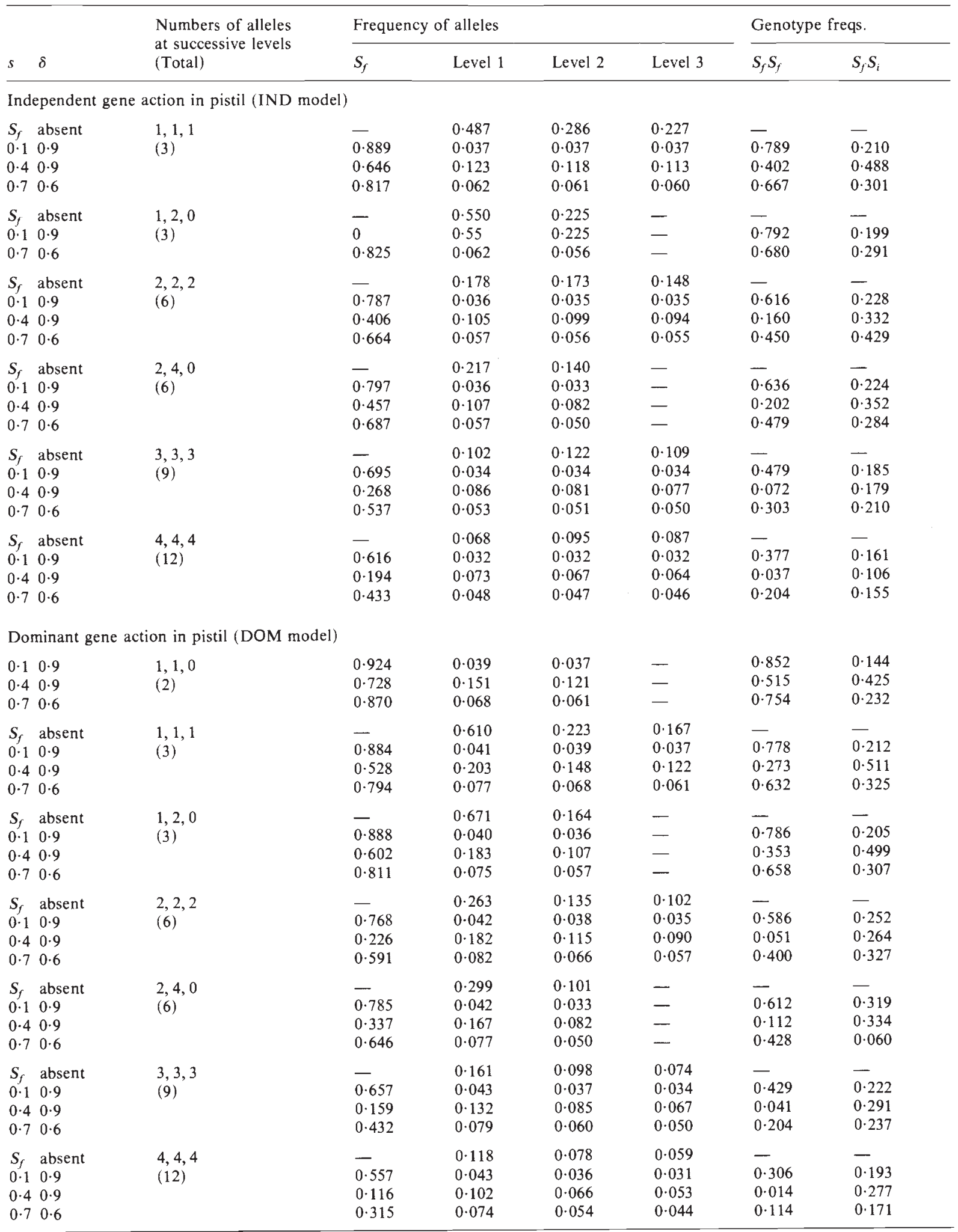


present, the rate of increase of new alleles was smaller than this. For example, assuming the IND model with two alleles present at each of three dominance levels, the rate of increase of a seventh allele was 1.073 for an allele at the most recessive level, and 1.063 for one at the most dominant level. If four active alleles were already present, these rates were 1.0548 and 1.0551 , respectively. In other words, the rate of increase was least for the most recessive alleles, and decreased with increasing numbers of pre-existing active alleles, as one would expect. The DOM model gave similar results, but with slightly lower rates of increase, for the same parameter values.

At equilibrium with more than a few alleles, the alleles have similar frequencies, regardless of their level. This is true when the numbers of alleles at the different levels are the same or different. The equilibrium frequencies are lowest for the most dominant alleles, as noted by Imrie et al., (1972) and Sampson (1974) but the differences are slight. The lower frequency of dominant alleles, compared with more recessive ones, has been found in genetic studies of self-incompatible species with sporophytic systems (Ockendon, 1974). For alleles at any level, the equilibrium frequencies are equal, except for the lowest recessive level of active incompatibility alleles, in which the alleles do not change in frequency from their initial values, so that an allele which is initially rare remains so, but is not lost (see also Sampson, 1974). Cope (1962) studied a model with multiple alleles in a hierarchy, with each allele dominant to alleles below it in rank (equivalent to a single allele at each of several levels in the version of the present model that assumes dominance of alleles at different levels, in the pistil as well as the pollen). Cope showed that the frequencies of all incompatibility types are equal, at equilibrium, which results in a decreasing allele frequency at equilibrium as the level of dominance increases. The results of runs using that model, but with more than one allele per level, and with a self-compatibility allele also present, are similar to those for the IND model (see table 3 ). Each incompatibility type reaches the same equilibrium frequency, and at equilibrium the allele frequencies are also very similar to one another.

\section{Comparison with the gametophytic case}

I have also done runs assuming gametophytic control of pollen reactions and independence in the pistil. As expected intuitively (see above), such alleles come to lower equilibrium frequencies than when sporophytic control is assumed, for the same parameter values. In all cases, the gametophytic system had a higher frequency of the $S_{f} S_{f}$ genotype, and a lower total frequency of selfincompatible genotypes, than the comparable sporophytic case (detailed results not shown). For example, with nine active $S$ alleles, the equilibrium frequency of the $S_{f}$ allele was $0 \cdot 151$ with sporophytic control and dominant action in the pistil, assuming $f=1, s=0.4$ and $\delta=0.9$; the frequency of the $S_{f} S_{f}$ genotype for this case was 0.023 . With independent action, the corresponding frequenices were 0.268 and 0.072 for the allele and the homozygous genotype, respectively, and with gametophytic action the frequencies were 0.436 and 0.186 assuming that heterozygotes for this allele were self-incompatible. The equilibrium frequency of $S_{f}$ for the gametophytic case was somewhat lower if heterozygotes for the $S_{f}$ allele and active $S$ alleles were more self-compatible, as would be expected intuitively since now the difference between $S_{f}$ and the active $S$ alleles is less. However, the effect was not very great. For the parameter values given above, if heterozygotes were assumed to have a selfing rate of $0 \cdot 2$ i.e., half that of the $S_{f} S_{f}$ homozygote, the equilibrium frequency of $S_{f}$ was 0.397 .

\section{Results of two-allele models}

One may wonder why two-allele sporophytic selfincompatibility systems are not found, since they appear possible a priori. Once a self-incompatibility allele has spread into a population with a recessive self-compatibility allele, a second allele, causing a different incompatibility type, and dominant to the first allele in both pistil and pollen, might arise. The population would then contain two self-incompatibility types, controlled by $S_{1}$ when homozygous and $S_{2}$ when heterozygous, and the self-compatibility allele would presumably be lost under the same conditions as those that guarantee the maintenance of the distylous type of self-incompatibility (Charlesworth and Charlesworth, 1979a). There seems no obvious reason why such mutations should not occur. However, no case of such a situation is known, even though it would be easy to analyse genetically and is therefore unlikely to exist, but to have been overlooked.

When one does runs with an initial $S_{f}$ allele and two active $S$ alleles with the properties required by this model, the results are not as described above, but the $S_{f}$ allele remains present in the population instead of being eliminated (table 3 ). This seems to be because this allele has 
a considerable advantage due to its ability to produce the self-compatible genotype. The situation is thus different from that studied previously (Charlesworth and Charlesworth, 1979a) in which distyly can be stable to the introduction of the homostylous self-compatible form (with the pollen having one of the incompatibility types and the stigma the other). That type of self-compatibility, however, has a smaller advantage than the type due to an $S_{f}$ allele, which abolishes all incompatibility reactions, because plants remain incompatible as male or as female with one or other of the incompatible types; pollen of the $S_{f} S_{f}$ genotype, however, can fertilise all other genotypes.

\section{CONCLUSIONS}

The chief conclusion of these models is that, if self-incompatibility evolves by the mechanism studied here, populations with active $S$ alleles with sporophytic action will have higher frequencies of the self-incompatibility alleles, and more selfincompatible individuals, than when there is gametophytic action. If self-compatibility alleles exist with the properties of the $S_{f}$ allele assumed here, populations with sporophytic or gametophytic self-incompatibility are also likely to have self-fertility alleles present, and their frequencies may be high unless both $s$ and $\delta$ are high. Even with a selfing rate of 0.4 for the self-compatible homozygote, and inbreeding depression of $0 \cdot 9$, the equilibrium frequency of $S_{f}$ in the most favourable case for loss (that of dominant allele action in the pistils of heterozygotes) was 0.116 when twelve alleles were present. This corresponds to a frequency of the self-compatible genotype of 0.014 , and the frequency of heterozygotes for the self-compatibility allele was $0 \cdot 277$. Such populations therefore have intermediate selfing rates, as previously found also by Charlesworth and Charlesworth (1979b) for the case of gametophytic action, when self-compatibility alleles are introduced into the population. This situation is different from other models that yield intermediate selfing rates as their evolutionary outcome (reviewed in Charlesworth and Charlesworth, 1987), in that it arises from the nature of the genetic control of the compatibility versus incompatibility.

It is therefore possible that species may be hard to classify clearly as self-incompatible or selfcompatible. One would expect to find differences between genotypes in their compatibility, and there could be differences between populations as well, given the low equilibrium frequencies of individual active $S$ alleles in many circumstances. If there are also weak incompatibility alleles, the problems would be even worse. The present paper does not contain any study of such weak alleles, because there is a possibility that they may be involved in "cryptic" incompatibility which is known is several sporophytic incompatibility systems (Bateman, 1956; Weller and Ornduff, 1977). When this occurs, pollen with a weak incompatibility type may be able to effect fertilization when it is present on a certain genotype of stigma, but be partly or completely unable to father progeny when a pollen type that is more compatible with that female genotype is also present (Casper et al., in press). The mechanism of this effect is not known, but it is likely that slow growth of weakly incompatible pollen tubes is possible. Since it is not reasonable to assume that stigmas of plants in nature would receive only one type of pollen, a study that includes weak alleles must thus incorporate a more complex mating model than the one used here. Weak incompatibility alleles may also show interactions that have not been considered in the model studied here, in particular mutual weakening of the pollen reactions may occur, giving the appearance of self-compatibility (Sampson, 1960; Thompson, 1972). Given the difficulties of establishing the inheritance of self-incompatibility when control is sporophytic, with dominance of some alleles over others, one would expect that clear genetic analysis of such species would be rare. These considerations suggest that sporophytic systems may be more common than previously thought, but may have been overlooked because of these difficulties.

The results given here are also relevant to the question of the maintenance of sporophytic selfincompatibility systems. It is clear that, at least in the very long term, such systems are subject to invasion by self compatibility alleles. However, if the self-compatibility $\left(S_{f}\right)$ allele arose by mutation at very low frequency, it would be present only in the heterozygous state, and since it has been assumed to be recessive to all active $S$ alleles, its phenotypic effect of increasing the selfing rate would not be manifested and it would spread very slowly until it reached a high enough frequency for homozygotes to occur. One might therefore expect some populations to lose the self-compatibility allele and not to regain it. The situation is thus different from that in a gametophytic selfincompatibility system, in which a self-compatibility allele does not behave as a recessive, because it can cause self fertilization when present in a heterozygote, and loss of self-incompatibility due 
to spread of mutations at the $S$ locus is expected to occur whenever the conditions for maintenance of self-incompatibility cease to be satisfied. This suggests that gametophytic systems are more unstable to the occurence of this type of self compatibility mutations than are sporophytic systems. Unfortunately, we do not know enough about the inheritance of self-compatibility in sporophytic systems to know whether recessive self-compatibility alleles at the $S$ locus are involved, or whether self-compatibility is most often due to alleles at other loci. At present, it is known that unlinked loci that affect the amount of the incompatibility protein can have such an effect (Sampson, 1960; Nasrallah and Wallace, 1967). Mutual weakening interactions between weak incompatibility alleles, which tend to be recessive, have also been implicated in self-compatibility (Thompson and Taylor, 1971).

Of course, the results given here are based on a purely speculative model, and different results would almost certainly be produced by different models for the initial evolution of self-incompatibility from self-compatibility, as well as for the maintenance of incompatibility once it is present in a population. However, in the absence of any clear understanding of how self-incompatibility has evolved, it seems worthwhile to think carefully about possible model systems. So far, origin from an $S_{f}$ allele seems to be the only obvious possibility. However, great progress is at present being made in understanding the nature of self-incompatibility alleles in both sporophytic and gametophytic systems (Nasrallah et al., 1985, 1987; Takayama et al., 1987; Anderson et al., 1986). It may therefore soon be possible to do more than just speculate about their origin. Once sequence data for several alleles are available, one may hope that it will be possible to construct "phylogenies" of these alleles and that this may shed light on the question of whether there was an ancestral allele.

The alleles that have so far been sequenced in Brassica, (Nasrallah et al., 1987; Takayama et al., 1987) which has a sporophytic system, differ by several amino acids. This is what one would expect to find if the different alleles evolved from an ancestral inactive allele, assuming that the only alleles likely to invade the population would be ones with new $S$ specificities not already present (Charlesworth and Charlesworth, 1979b); thus new alleles arising by mutation would be unlikely to spread if they occurred in alleles that were already active in the population, but an allele derived from $S_{f}$ by changing a different amino acid site from those present in existing alleles could invade, provided that it produced a protein with an $\mathrm{S}$ specificity. Different alleles produced in this way would therefore differ by at least two amino acids from one another. This assumes that at least a weak specificity can be produced by a change in one or a small number of amino acids, and that different specificities can coexist in a single allele, i.e., that cross-reacting alleles can potentially exist (see Lewis, 1962). This possibility should be empirically testable, if alleles could be produced by recombination between different $S$ alleles, or by mutagenesis. If most amino acid changes to active alleles leave their $\mathrm{S}$ specificity unchanged, or abolish it, one would have to conclude that specificity differences require many differences in the $S$ protein. If many changes produce entirely new specificities, one would have to conclude that the multiple differences between alleles are mostly ones without effect on the specificity.

The absence of two-allele sporophytic selfincompatibility seems to be due to the fact that $S_{f}$ alleles have a strong tendency to persist in populations with such systems, even when inbreeding depression is quite high. Such populations are therefore vulnerable to the fixation of such alleles, which would quickly occur if inbreeding depression should become lower for several generations. If, however, inbreeding depression remains very high such populations are likely to be invaded by further active alleles.

The reason why systems with the properties of the self-incompatibility found in distylous species are controlled by more than one locus, as appears to be the case (Baker, 1966; Ernst, 1936), instead of by alleles at a single locus, is probably because the incompatibility reaction in these plants is not mediated by identity of some pollen and pistil substance (oppositional system, see Bateman, 1952), but by recognition reactions between one substance in the pistil and a different one in the pollen (complementary or lock-and key system); one would expect the "lock" and the "key" to be under the control of separate genetic loci.

Acknowledgements I thank B. Charlesworth for helpful discussions, and for reading a first draft of this paper. This work was supported by NSF grant BSR-8516629.6. 


\section{REFERENCES}

ANDERSON, M. A., CORNISH, E. C., MAU, S-L., Williams, E. G., HOGGART, R., ATKINSON, A., BONIG, I., GREGO, B., SIMPSON, R., ROCHE, P. J., HALEY, J. D., PENSCHOW, J. D., NIALI, H. D., TREgEAR, G. W., COGHLAN, J. P., CRAWFORD, R. J. AND CLARKE, A. E. 1986. Cloning of CDNA for a stylar glycoprotein associated with expression of self-incompatibility in Nicotiana alata. Nature, 321, 38-44.

BAKER, H. G. 1966. The evolution, functioning and breakdown of heteromorphic incompatibility systems. 1. Plumbaginaceae. Evolution, 20, 349-368.

BATEMAN, A. J. 1952. Self-incompatibility systems in angiosperms. 1. Theory. Heredity, 6, 285-310.

BATEMAN, A. J. 1956. Cryptic self-incompatibility in the wallflower: Cheiranthus cheiri L. Heredity, 10, 257-261.

BEACH, J. H. AND KRESS, W. J. 1980. Sporophytic versus gametophytic: a note on the origin of self-incompatibility in the flowering plants. Syst. Bot., 5, 1-5.

CASPER, B. B., SAYIGH, L. S. AND I.EE, S.S. 1988. Demonstration of cryptic incompatibility in distylous Amsinckia douglasiana. Evolution, in press.

CHARLESWORTH, B. AND CHARLESWORTH, D. 1979a. The maintenance and breakdown of distyly. Amer. Nat., 114, 499-513.

CHARLESWORTH, D. AND CHARLESWORTH, B. $1979 b$. The evolution and breakdown of self-incompatibility systems. Heredity, 43, 41-55.

CHARI.ESWORTH, D. AND CHARI.ESWORTH, B. 1987. Inbreeding depression and its evolutionary consequences. Ann. Rev. Ecol. Syst., 18, 237-268.

COPE, F. W. 1962. The effects of incompatibility and compatibility on genotype proportions in populations of Theobroma cacao. Heredity, 17, 183-195.

DE NETTANCOURT, D. 1977. Incompatibility in Angiosperms. Springer-Verlag, Berlin.

ERNST, A. 1936. Weitere Untersuchungen zur Phänanlyse zur Fertilitätsproblem und zue Genetik heterostyler Primeln. II. Primula hortensis Wettstein. Arch. Julius-Klaus Stfitung Vererbungsforsch. Sozialanthropol. u. Rassenhygiene, 11, 1280.

FUCHINOUE, Y. 1979. Analysis of self-incompatibility alleles of major varieties of tea. Japan. Agric. Res. Quarterly, 13, 43.

GANDERS, F. R. 1979. The biology of heterostyly. New Zeal, J. Bot., 17, 607-635.

GERMAIN, E., l.EGLISE, P. AND DELORTY, F. 1981. Analyse du système d'incompatibilité pollinique observé chez le noisetier Corylus avellana L. $1^{\text {er }}$ Colloque sur les Récherches Fruitières, Bordeaux, pp. 197-216.

GIBBS, P. E. 1986. Do homomorphic and heteromorphic selfincompatibility systems have the same sporophytic mechanism? Pl. Syst. Evol., 154, 285-323.

GIRBS, P. E. AND FERGUSON, I. K. 1987. Correlations between pollen exine sculpturing and angiosperm self-incompatibility systems - a reply. Pl. Syst. Evol., 157, 143-159.

HUMMEL, R. I.., ASCHER, P. D. AND PELLETT, H. M. 1982. Genetic control of self-incompatibility in red-osier dogwood. J. Hered, 73, 308-309.

IMRIE, B. C., KIRKMAN, C. T., AND ROSS, D. R. 1972. Computer simulation of a sporophytic self-incompatiblity breeding system. Aust. J. Biol. Sci., 25, 343-349.

JACOB, v. J. 1980. Pollination, fruit setting and incompatibility in Cola nitida. Incompatibility Newsletter, 12, 50-56.

KOWYAMA, Y., SHIMANO, N. AND KAWASI, T. 1980. Genetic analysis of incompatibility in the diploid species of Ipomoea closely related to the sweet potato. Theoret. Appl. Genet., 58, 149-155.
LANDE, R. AND SCHEMSKE, D. W. 1985. The evolution of self fertilization and inbreeding depression in plants. 1. Genetic models. Evolution, 39, 24-40.

LEWIS, D. 1962. The generation of self-incompatibility alleles. J. Theoret. Biol., 2, 69-71.

LLOYD, D. G. 1979. Some reproductive factors affecting the selection of self fertilization in plants. Amer. Nat., 113, 67-79.

LUNDKVIST, A. 1979. One-locus sporophytic self-incompatibility in the carnation family, Caryophyllaceae. Hereditas, 91, 307 (Abstract).

MARTIN, F. W. 1968. The system of self-incompatibility in Ipomoea. J. Hered., 59, 263-267.

ME, G. AND RADICATI, L. 1983. Studies of pollen incompatibility in some filbert (Corylus avellana $L$.) cvs. and selections. In Mulcahy, D. L. and Ottaviano, E. (eds.) Pollen: Biology and Implications for Plant Breeding, Elsevier, New York, pp. 237-242.

MUENCHOW, G. A. 1982. A loss-of-alleles model for the evolution of distyly. Heredity, 49, 81-93.

NASRALLAH, J. B., KAO, T-H., CHEN, C-H., GOLDBERG, M. I. AND NASRALiAH, M.E. 1987. Amino-acid sequence of glycoproteins encoded by three alleles of the $S$ locus of Brassica oleracea. Nature, 326, 617-619.

NASRALLAH, J. B., KAO, T-H., GOLDBERG, M. L. AND NASRALLAH, M.E. 1985. A cDNA clone encoding an Slocus-specific glycoprotein from Brassica oleracea. Nature, $318,263-267$.

NASRALI.AH, M. E. AND WAll.ACE, D. H. 1967. Immunogenetics of self-incompatibility in Brassica oleracea L. Heredity, 22, 519-527.

OCKENDON, D. J. 1974. Distribution of self-incompatibility alleles and breeding structure of open-pollinated cultivars of Brussels sprouts. Heredity, 33, 159-171.

PANDEY, K. K. 1958. Time of S-allele action. Nature, 181, $1220-1221$.

PANDEY, K. K. 1960. Evolution of gametophytic and sporophytic systems of self-incompatibility in angiosperms. Evolution, 14, 98-115.

SAMPSON, D. R. 1960. An hypothesis of gene interaction at the $\mathrm{S}$ locus in self-incompatibility systems of angiosperms. Amer. Nat., 94, 283-292.

SAMPSON, D. R. 1974. Equilibrium frequencies of sporophytic self-incompatibility alleles. Can. J. Genet. Cytol., 16, 611618.

TAKAYAMA, S., ISOGAI, A., TSUKAMOTO, C., UEDA, Y., hINATA, K., OKAZAKI, K. AND SUZUK1, A. 1987. Sequences of S-glycoproteins, products of the Brassica campestris self-incompatibility locus. Nature, 326, 102-105.

THOMPSON, K. F. 1972. Competitive interaction between two $\mathrm{S}$ alleles in a sprophytically-controlled system. Heredity, $28,1-7$

THOMPSON, K. F. AND TAYIOR, J. P. 1971. Self-compatibility in kale. Heredity, 27, 459-471.

THOMPSON, M. M. 1979. Genetics of incompatibility in Corylus avellana L. Theoret. Appl. Genet., 54, 113-116.

WELlER, S. G. AND ORNDUFF, R. 1977. Cryptic self-incompatibility in Amsinckia grandiflora. Evolution, 31, 47-51.

WHITEHOUSE, H. L. K. 1950. Multiple-allelomorph incompatbility of pollen and style in the evolution of the angiosperms. Ann. bot. ns., 14, 198-216.

ZAVADA, M. S. 1984. The relation between pollen exine sculpturing and self-incompatibility mechanisms. Plant Syst Evol., 147, 63-78.

ZAVADA, M. S. AND TAYLOR, T. N. 1986. The rôle of selfincompatibility and sexual selection in the gymnosperm angiosperm transition: a hypothesis. Amer. Nat., 128, 538 550 . 